\title{
Formation and Evolution of Early Intervention for Children with Developmental Delays in Russia and Abroad
}

\section{Anna I Akhmetzyanova*}

Institute of Psychology and Education, Republic of Tatarstan, Russian Federation

\begin{abstract}
The urgency of this issue is due to the uniqueness of infancy that is recognized as one of the most significant in the development of a number of child's psychological functions. System of early intervention provides the widest coverage of children with developmental delays at early stages of ontogenesis that contributes to the prevention of secondary delays and to the most effective use of sensitive periods in the development of higher physical functions for children's recovery and growth. The history of formation and evolution of early intervention system in the Russian Federation and abroad will be reviewed in the framework of this research.
\end{abstract}

Keywords: Early aid; Early intervention; Developmental disabilities; Child with special educational needs

\section{Research Actuality}

For the first time the issue of providing early support for children with developmental disabilities was raised in foreign special education. The urgency of this issue is due to the uniqueness of infancy. According to N. M. Aksarina, L. I. Bozovic, J. Bowlby, L. A. Venger, L. S. Vygotsky, A. V. Zaporozhets, V. S. Mukhina infancy is recognized as one of the most significant in the development of a number of child's psychological functions, at this age in particular motor functions, cognitive orientation, speech and child's identity are in the process of formation. Ontogenetic immaturity of morphofunctional systems is a distinctive state of a newborn baby brain. At this moment brain plasticity defines great potential for the correction of impaired or developmentally delayed functions.

Early adequate care provided for a child allows to more effectively compensate psychophysical developmental disabilities, thereby mitigating and possibly avoiding secondary deviation. System of early intervention provides the widest coverage of children with developmental delays at early stages of ontogenesis that contributes to the prevention of secondary delays and to the most effective use of sensitive periods in the development of higher physical functions for children's recovery and growth. The earliest possible initiation of comprehensive psychological-medical-pedagogical support for the family who takes care of a child with special educational needs is the factor for optimizing child's educational opportunities and socioeconomic perspectives. It is a step towards improvement of practice related to the protection of children rights and rights of children with disabilities, qualitative improvement of their position in society.

In many countries this triggered formation of a new system of early childhood services targeted at children shortly after birth and their families. This system acquired the term Early Intervention or in generally accepted translation into Russian language «Раннее вмешательство». Early intervention is a system of coordinated services designed to promote the development of children with impairments or at risk of emerging disabilities and support their parents, it also includes identification of problems in a child's development and assessment of developmental characteristics.

In different countries the scope of a comprehensive care provided for children with developmental delays, including children with disabilities and their families has several major sources: healthcare system, educational system, social protection system and nongovernmental organizations.
The above-mentioned activity has several terms: Early Childhood Intervention (ECI), Early Aid (EA), and Early Support. In most countries more than one term is used at the same time. For example, in Germany there are social pediatric centers delivering early childhood intervention services in healthcare system and early support centers in educational system. Early Intervention and Early Aid terms are also used in the Russian Federation. The term Early Childhood Intervention gained widespread currency.

In most countries due to the initial agency affiliation or legal status of organization within whose structure those services are established there are several approaches to the provision of early intervention for children and families.

\section{Medical approach}

Services mainly aimed at early detection, treatment, rehabilitation, primary and secondary prevention of developmental delays are usually established within the healthcare system. Most members of medical staff are physicians who play a key role in the functioning of the services.

\section{Psycho-pedagogical approach}

Services focused to a greater extent on special education of children with identified developmental delays and tertiary prevention perform a psycho-pedagogical approach. Mostly such services are established within the educational system or non-governmental organizations.

\section{Social pedagogical approach}

Services focused on social adaptation of children with identified disabilities or children at high psychosocial risk for developmental delays represent a social pedagogical approach to the provision of early support. Such services are usually established within the system of social protection or non-governmental organizations.

*Corresponding author: Anna I Akhmetzyanova, associate professor, Deputy Director of Research, Institute of Psychology and Education, Federal University, Kazan (Volga region), 18 Kremlevskaya St., Kazan, 420008, Republic of Tatarstan, Russian Federation, Tel: 8 (987) 290-46-23; E-mail: Anna.Ahmetzyanova@kpfu.ru

Received October 12, 2015; Accepted February 22, 2016; Published February 29, 2016

Citation: Akhmetzyanova $\mathrm{Al}$ (2016) Formation and Evolution of Early Intervention for Children with Developmental Delays in Russia and Abroad. J Psychol Abnorm S1: 006. doi:10.4172/jpab.S1-006

Copyright: (c) 2016 Akhmetzyanova Al. This is an open-access article distributed under the terms of the Creative Commons Attribution License, which permits unrestricted use, distribution, and reproduction in any medium, provided the original author and source are credited. 


\section{Comprehensive approach}

Services created within non-governmental organizations [1] or new organizations of the municipal level functioning outside the healthcare, educational and social protection systems enjoy more freedom in establishing a comprehensive approach which includes balanced components of medical, educational and social purposes.

\section{Partnership approach}

The practice of early support in many countries indicates that there is a competition and serious difficulties in overcoming the barriers between services that have different legal framework of activity [2]. In such cases, one of the most promising ways to create the unified system of early intervention is to develop a clear separation of different services and establish well-functioning and constructive interaction between them [3].

One of the most quoted definitions of early support belongs to Guralnick who defines early childhood intervention as a system designed to support family patterns of interaction that the best promote child's development [4]. Alisauskiene shares this point of view adding that early intervention should result in social inclusion of family and child [2].

Such concept of early intervention nature (family-centered approach) is rapidly gaining increasingly more supporters and vastly differs from assumptions common in the 60 's- 80 's of the $20^{\text {th }}$ century when all activity of early intervention services was focused on children (child-centered approach), medical rehabilitation and early special education.

Early intervention programs in the Russian Federation have two goals. The first goal general for the whole world is to identify deviations in the development of an infant or young child as early as possible and support parents in providing optimal conditions for a child's development and education in the context of family and local community. Early intervention programs include the entire process starting with detection of child's developmental problems, multidisciplinary assessment, therapy treatment and support up to child's transition to the preschool or other institution. With increasing frequency prenatal diagnosis is said to be an obligatory element of early intervention programs as its psychological consequences are very important for parents and therefore require inclusion of this process into the sphere of early intervention.

The second goal which is specific for the Russian Federation where there is still a large number of children living in residential care institutions (children's homes, orphanages, residential care homes) is to prevent child's separation from his/her family and avoid placement in an orphanage. Experience learnt from the early intervention programs provided in Russia shows that these programs aimed at supporting families of young children with functional impairments gained a good reputation of social orphanhood prevention programs for children with disabilities [5].

Development and implementation of early intervention programs helps to keep a child in the family and prevent parents from surrendering their children with the subsequent transfer to the state institutions for orphans and children left without parental care.

One of the main goals of early intervention is to create conditions for fulfilling special needs of children in infancy and early childhood so that at the following stage of their development they might be included in community of peers and attend preschool institutions. Early intervention is technology of preventing child's disability by using professional support of child's strong points and satisfaction of his/her needs, integration and adaptation to the family, peers and society in general. In this case it should be mentioned that we are talking about the social model of disability which is based on the concept of equal rights and equal opportunities for all people in society and the concept of life normalization. Normalization does not mean that a child with disabilities becomes "normal", i.e. having no deviations. This term means that child's life becomes normal, the same as other children of his/her age have due to the removal of barriers that precluded a child from living a normal life and being involved into the same activities as his/her peers.

\section{Early Childhood Intervention Programs Provide}

\section{Early detection of developmental delays and disabilities}

It is proved that support is more efficient if initiated as early as possible. Therefore, one of the most important tasks of early childhood intervention programs is early identification of developmental delays and disabilities. Undoubtedly, medical institutions and medical professionals are of enormous importance in diagnostics. Sometimes developmental delays are detected shortly after a child was born or even as a result of prenatal diagnostics. In such circumstances it is crucial for the family to be immediately directed to get early intervention services. However, as it happens often enough a child may not have a revealed diagnosis, but may be lagging in development. In this case the role of early intervention is to conduct an appropriate screening and possibly determine the cause of emerging developmental delays. Early intervention services must respond to the request of any family concerned about the development of their child. Precisely this approach allows identifying possible risks and developmental delays as early as possible.

\section{Informational and psychological support for families}

A moment of revealing the diagnosis is a critical for parents and for the further fate of a child. The way the diagnosis is disclosed often influences the family decision on whether to accept or abandon a child, as well as it influences the emotional state of parents and their ability to provide adequate care for a child. For a small moment not only the image of a child who had been waited for, but all the ideas about the future crash down. When parents find out that there is "something wrong" with their child, they are shocked. The most family needs at this moment is support and understanding. The researches reveal that in addition to the empathy and psychological support of close friends and professionals, parents primarily need accurate and adequate information. The process of accepting and perceiving a child's diagnosis can take a long time, sometimes it takes years. The process is especially difficult in case the family has not received sufficient information, information was insufficiently available or misreported, parents were not able to get a psychological and emotional support to cope with their own feelings, or without the support of near and dear ones they were also deprived of professional assistance.

Parents need assistance in order to cope with feelings, gain strength and confidence. Information is needed to start acting with awareness of child's characteristics and resources that may be helpful for a child's development.

\section{Aid and support delivered to families for mobilizing their resources and ensuring interaction with other resources in society and immediate environment}

Specialists providing early intervention services focus on family rather than their child. For infants and young children their parents 
are the most crucial factor in their social environment, so the efficiency of working with the child's environment is much higher than working with a child without consideration of the social context, namely his/ her parents. It is important to note that parents are not clients of the services, but rather partners whose opinion and knowledge is respected while developing programs. Parents of a child with disabilities, in their turn, need support that would allow themselves to feel confident and competent in the areas of education and development, in understanding their child's needs.

The main task of specialists is not only to provide special sessions for a child, but also to help parents and immediate surroundings to mobilize their potential for promoting a child's development. Moreover, it is important to think about the support that family can get in community. Sometimes families of children with severe disabilities need services of a volunteer who can take care of a child while his/ her mother is busy with other important matters. Family may face difficulties in finding necessary resources that parents often do not even know their child has a right to, or do not know that this may be significant for a child's development (special allowances, provision of assistive technology device, social taxi services and so on).

Precisely professionals of the services should inform about resources available for the family.

\section{Systematic assessment of child's development level}

Early intervention programs use the term "interdisciplinary dynamic assessment". This term means that different experts integrate their findings by using their professional assessment in order to develop the unified description of strong points in a child's development and identify problem areas. The overall objective is to use this assessment as the base for the development of an intervention program plan. This is slightly different from the traditional diagnostic system focused on child's developmental delays or his/her diagnosis. In such traditional model diagnostics is aimed at detecting negative deviations from the norm and involves defining child's problems, focusing mainly on the description of developmental delays. However, no matter how detailed the developmental delay description is, it does not include other factors that significantly affect the quality of life and child's development, for example, his/her individual capacity, interests, environment, family situation, concomitant somatic diseases and other factors. Undoubtedly, detection of diagnosis is extremely important in early intervention programs, but we must remember that a comprehensive assessment of a child's capacity helps to achieve a maximum effect in implementing the assistance program. The purpose of assessment in early intervention is to define the actual child's resources and potential of a child's development. Assessment is a hypothesis about a child's development capacity that is constantly updated and adjusted over the course of the program. The process of assessment used in early intervention programs is continuous and does not end at its initial stage. It is important to follow the process of a child's development and simultaneously analyze the course of the intervention process in order to timely review the goals and methods of the assistance programs due to the changes in a child's development.

\section{Development and implementation of individual intervention program in cooperation with family}

Early intervention programs are developed individually and based on assessment of child's and family needs, as well as their capabilities. Distinctive feature of early intervention programs is their long-term effect. This means that once the family is involved into the program, professionals will accompany the family for quite a long time. It can take several months, but more often program for children with disabilities may last for several years until the moment when a child begins to attend preschool, some services accompany children up to school age. Intensity of the program is also defined individually due to the family's capabilities, early intervention services, child and family needs. Basically family meets a child no more than 1 time per week. Early intervention program cannot be characterized as courses, the way it often practiced in the rehabilitation system. The process of young children's development proceeds constantly, faster or slower for someone. It is impossible to speed up the development by using intensive program over the short term period and then leave the family without professional support for a long time. It is crucial for the families to have constant support from specialists, so that they can regularly discuss with professionals their questions and changes in child's condition. This is significant for parents from both psychological and child's development perspective. Early intervention program must be flexible and be adjusted to the changing needs of a child and his/ her family. For this purpose it is important to ensure that parents are involved in the process at all stages of the program development and implementation. A more detailed description of the program evolution will be given in the following chapters.

\section{Coordination and cooperation with other agencies providing services for a child and his/her family}

Depending on a child's condition and deviation family may require a variety of additional resources. Early intervention is an interdisciplinary program in itself, but even such team is not always able to resolve all the issues related to ensuring quality of life for children with disability and their families. There are a number of needs, such as medical services or legal support that cannot and should not be provided for the family within early intervention programs. However, especially early intervention service often becomes the main coordinator of services created for a child and his/her family. Interaction between early intervention services and agencies of the healthcare, social protection, educational systems is needed to address the major challenges and ensure effective functioning of the services. In particular, interaction with the agencies of the healthcare system (maternity hospitals, children's hospitals, medical centers) is necessary to ensure the identification and referral of children in need to early intervention programs. It is crucial to have information on early intervention programs available in the aforementioned institutions for the families to receive timely information and referrals to early intervention programs. Specialists of early intervention services should promote the development of the child's transition plan from early intervention services to preschool, and also ensure referral to other appropriate services in order to be provided with necessary services and support, such as medical or social. It is important to inform families about available legal services. Another task is to help families to get acquainted with the enormous flow of various techniques, methods of treatment and rehabilitation offered by a variety of organizations, professionals and unfortunately, often by non-professionals promising miraculous healing and deliverance from all the problems.

\section{Organization of support groups for parents}

Organization of parent support groups where parents are themselves therapists for each other is a quite common phenomenon. Early intervention services often become a foundation for the motivated parents to organize their own clubs and groups. Sometimes such clubs bring forth independent parent organizations. It is important for parents to communicate with each other, discuss common problems and understand that they are not alone in their grief, feel the support of 
people who have been through similar situations, have experienced the same feelings and emotions. The role of an expert might be minimal. At the early stages when parents are in great need of information and support of professionals, greater involvement of early intervention team members is required. The role of a specialist can gradually alter from a leading to an assistant. Experience shows that subject and organizational forms of such groups can be very diverse. It can be mixed parent-child groups where families come together with their children or groups for parents only. Activity framework depends on creativity of the services specialists and parents, as well as the level of trust and the atmosphere created in early intervention services in general.

\section{Historical Perspective}

Erich Fromm and John Bowlby were the first to address the issue of early childhood. They considered the social environment not only as a condition but the most essential factor for the development of identity. Environment is understood by E. Fromm as an immediate child's surrounding, family, near and dear ones. The importance of the social environment, including child's family, was discovered by the British psychologist and psychiatrist J. Bowlby in the attachment theory (1958). The content of the theory reveals that main problems experienced by children through the socialization process are related to the failure of communication with their parents, lack of parental warmth and care at an early age. According to the idea formulated by the scientist there is the bond between mother and child during his/her first few months of life that cannot be referred to any sexuality or instinctive behavior. Sharp breakdown of such relations causes serious disturbances in mental development, primarily in the structure of identity. Such disorders may not be revealed immediately, but much later. J. Bowlby's studies have found that children in close emotional contact with their mothers show better results in terms of the level of cognitive activity than those children who grew up in 'cold' families [6]. According to the foreign experts, namely Winnicott, Mahler et al., Ainsworth et al., Stern, Kraus \& Jacobs formation of the attachment between mother, infant and child's identity depends largely on the experience obtained from the interaction with child's mother at the earliest stages of development. This concept is particularly important while considering and analyzing children with special needs, particularly premature infants, infants with Down syndrome and infants with other risk factors [7]. Analysis of the theories provides valuable material for understanding the essence of support delivered for children with developmental disabilities and helps to identify the following conceptual fundamentals: understanding of selfhood and child's interests, assistance in self-esteem that will encourage a positive child's development. Early life periods play a special role in the development of identity. A person is primarily a social being and therefore cannot develop without interaction with the child's surrounding and immediate environment that is first of all his/her family and friends. Scientific substantiation of the theory of human development in infancy and early childhood (from birth to age 3) significantly affected the practical change in organizational forms of the services provided abroad for infants and led to the creation of interdisciplinary programs focused on infants and their families [8].

In the 60 's -80 's of the $20^{\text {th }}$ century attention of researchers in many European countries was focused on the specific difficulties experienced by children. Activities with involvement of different specialists were organized to help children to overcome the disturbances. Parents' participation and their advice on children's development was an essential factor for the successful remedial work with those children that belong to the risk group. The age range was expanded for the children of remedial classes, for the first time groups for infants and preschoolage children were organized. The concept of normalization regardless of children's medical, genetic or any other individual differences developed by the Swedish scientist Bengt Nirje had become one of the conceptual frameworks in the development of early intervention programs. The second conceptual framework of the ongoing programs was the principle of integration. All conceptual frameworks were approved by the state policy of Western countries [9]. The programs of advanced education (Head Start Programs) that were applied in the course of the psychological growth of children with disabilities and activity limitations served as the starting point for the development of early aid or early intervention programs. They were based on the principles of a special significance of the first months and early years of life for the further child's development and intended for educational, social support of family and child while methods of interaction between family and the outside world were just beginning to emerge.

Early intervention groups in Europe were created simultaneously with early intervention programs in the United States. Early education program for children with Down syndrome was considered to be one of the first programs for children with multiple defects developed by L. Rhodes and a group of his colleagues in 1969 in the state hospital Sonoma in the USA. The program had demonstrated the effectiveness of pedagogical intervention. Early intervention services were established on the basis of the University of Washington for the purpose of testing the Small Steps Program (Sydney, Australia) of early pedagogical assistance for children with developmental disabilities. The above-mentioned program was designed to enhance the pedagogical development of children with mental, physical disabilities (from birth to age 4). The conceptual strategy of the Small Steps Program represented an innovative approach in the field of education for children with developmental disabilities. The main idea of this program was as follows: "All children can learn. A child with developmental disabilities learns more slowly, but he/she can learn!:" [10].

Based on the results of a significant number of studies in various areas of child's development the US Congress concluded that it is necessary to develop a comprehensive, coordinated, multidisciplinary and interagency program of early intervention services in order to reduce the probability of emerging developmental delays and increase the ability of families to fulfill special needs of infants and children. In 1986 the US Congress passed an amendment to the Individuals with Disabilities Education Act that had already been in force and regulated activity of all public institutions. The US Congress inserted the paragraph on children from birth to age 3 with developmental delays detected by the appropriate diagnostic methods in one or more of the following areas: cognitive development, physical development, language and speech development, self-help skills, social and emotional development. Thus, in the several US states early assistance started gaining the status of the social system with multiple structural, functional and content characteristics. All these processes made significant adjustments to the concept of early intervention and were considered not only as separate social-pedagogical or therapeutic programs, projects for infants and children of social and biological risk group and their families, but also as a complex of medical-social and psychological-pedagogical services [11]. Starting from the 1990s implementation of a holistic approach to identity development of a child with disabilities became the priority. It was understood and accepted that regardless of age a child needs maximum stimulating activity, self-dependence and responsibility for the results of his/her activity, whether it refers to the social or cognitive. New values, objectives and results provided the basis for the conceptual model of early intervention that was focused on education, outreach and awareness raising activity for parents and child's immediate environment. 
O. E. Emelina carried out a retrospective analysis of evolution of early childhood intervention system abroad and identified two main periods. The first period (from the 1960s to the 1980s) is characterized by conceptually new ideas revealing the role of society and the immediate environment in a child's development immediately after his/her birth. Child's family and friends are considered to be his/ her immediate environment that is the most important factor in the development of identity (E. Fromm, J. Bowlby). Meanwhile several researches were conducted to prove that mother is a reliable protection, a kind of foundation for her child and main problems experienced by children over the course of the socialization process are related to the failure of communication with their parents, lack of parental warmth and care at an early age. The second period of evolution (from the 1990s to the present) is characterized by the priority of implementing a holistic approach to a child's identity and development of a social pedagogic approach. The conceptual basis of the latter approach is the fulfillment of special needs in education and socialization of infants and children. The main component of this approach is focused on the individual development of children with special educational needs and choice of individual educational route with the involvement of all existing educational structures of the educational system, informational support for parents and their engagement in the implementation of the child's individual development plan, provision of the integrated training for parents and implementation of special programs aimed at child's education and socialization [12].

Further we will consider development and evolution of early intervention in Sweden in more details. Sweden occupies the leading position in the world for the quality of care provided for children with disabilities and children with different kinds of developmental delays. In 1967 in the wake of economic recovery in Sweden the new Act Concerning Support and Services for Persons with Certain Functional Impairments was adopted. The above-mentioned act presented and recognized state guarantees for the right to receive education and work; it also outlined the principle of integration and its objective as maximum inclusion of disabled and people with HIA (Health Impact Assessment) in society. Under new legislation the custodial institutions of the healthcare and social protection systems were forced out by the new forms of support, in particular habilitations, hostels and day-care centers. Development of the social sphere on the basis of the integration principle caused changes not only in the healthcare and social protection systems, but also affected the educational system. Sweden implemented the idea of institutionalization, having created the differential system of special education for many children in need. In these years Bengt Nirje authorized by "All - Sweden Union of children, adolescents and adults with mental retardation" articulated another principle of the social state policy, namely the principle of normalization.

In the late 60's - early 70's two fundamental principles were officially adopted in the field of the social policy in Sweden, in particular the principle of normalization of living conditions for disabled and people with HIA and the principle of integration. In the course of time the core of "integration" and "normalization" concepts in the social policy of Sweden had undergone significant changes. In today's Sweden these two principles mean accessibility and equality, provision of assistance, organization of social services and education on equal terms.

In the 80 's of the last century the public sector in Sweden was decentralized, so the system of early intervention in the country was mostly based on territorial (municipal) model. Three levels of providing early support with their goals, objectives and functions were identified within the structure of this model.
The first level is represented with children's health, social services and preschool institutions that among performing prevention, rehabilitation, treatment, social, care and education services also detect children with developmental disorders and undertake measures to prevent possible problems in their development. These services are visited by families with children from birth to age 6 . These services offer basic programs consisting of various developmental screening methods. Goals of children's health services stated by the Swedish National Board of Health and Welfare in 1981 were:

a) to decrease mortality, morbidity and disability among children;

b) to decrease harmful and distressing effects on parents and children;

c) to support parents in fulfilling their roles, thereby creating a favorable environment for the milestones of children's development.

If the results of diagnostic maneuvers by children's health service reveal any disabilities, a child is sent to the clinic or habilitation center for children.

The Swedish Education Act states that children are entitled to childcare from the age of 1 to 12 (after entering school this takes the form of leisure time centers) if parents work or study. Until 1998 childcare was the responsibility of the National Board of Health and Welfare, but since then, all childcare, leisure-time activities, compulsory education and upper secondary education have been incorporated under the National Agency of Education.

Children with HIA are entitled to childcare regardless of parents' employment because preschool education is considered as one of the main components of the Swedish system of early intervention. Children up to 18 months are usually educated at home (social insurance system provides one parent with the right to leave a job for this period), later most of the children attend different kindergartens. Before entering school children with HIA can be identified within these institutions that in conjunction with children's health and social services for ordinary families form the first level of preventing children's developmental delays. Children placed into the group due to the various reasons, are not usually singled out into specific structure within the kindergarten and do not receive any assistance. Children in need of specialized care are entitled to receive their place in the kindergarten out of turn. Their needs are fulfilled within the environment common for their peers.

At the second level early intervention system is presented with habilitation centers for children, children's psychiatric hospitals and social services. The habilitation centers are the separate municipal structures. The main activity of the center is based on the habilitation concept developed in Sweden. The core of the concept is not only a multi-faceted treatment, correction of existing problems in a child's development, "but also an opportunity to teach a child to achieve important functional goals by using alternative ways if the usual ones are blocked and adapt the environment in order to substitute missing functions". Evolution of the children's habilitation system in Sweden is subject to the principle of ensuring equal rights for all children, including children with HIA. In the children's habilitation center a child can get a comprehensive multidisciplinary medical, social, educational and emotional care. In the most severe cases some children are sent to the psychiatric clinics for children. The structure of the habilitation center in Sweden often comprises a lekotek, i.e. toy library. The concept of lekotek emerged in the mid-60's and the first lekotek was created in Stockholm by the initiative group of parents and teachers. 
At the third level provision of early intervention support for children with special needs and their families assumes more indirect forms, assistance is mainly targeted at the child's social environment, in particular medical consultation provided to the staff of educational institutions, special training for the teachers of preschools and other institutions.

The modern model of early intervention in Sweden is focused on the conceptual pattern, called "Model of System Development". However not all of the basic principles of this model are equally implemented and presented in the early intervention system formed in Sweden. In actual practice there is only a tendency towards multidimensionality and the emphasis is made on a child, in particular on comparing a child's development with developmental age norms. Most diagnostic and remedial measures are child-centered and little attention is paid to the interaction with parents and peers, evaluation of the environment and family. Individual approach is also under-represented in the practice of certain institutions.

One of the main problems of the Swedish decentralized system is ensuring the coordination of the various services engaged in early intervention system. Despite the decentralized nature of the early intervention system in Sweden, the National Board of Health and Welfare is responsible for maintaining the same level of health and social services quality throughout the country, meanwhile the Ministry of Education is in charge of maintaining the quality of educational services. Difficulties in the implementation of this unity are due to the fact that municipalities possessing considerable authority may fulfill the handed down directives in different ways.

The researchers emphasize the existence of organizational differences between the early intervention system formed in the United States and Sweden. The main difference is due to the principles these systems are based on, in particular on principles of rights or needs. Activity of the US services is based on the human right to access them if the person is found to be affected by any specific problems that are considered as "access criteria". In the United States there is no general practice of training or providing care for all young children and organization of this process is the entire responsibility of the child's family. Children get access to the services only after they have been detected certain problems or assigned to the risk group. Therefore, most of early intervention services in the United States are specialized and focused on specific groups of children or individuals. The family may receive insufficient amount of services, if the family does not claim its rights. In Sweden there is a system of early education and care for all children, including children with HIA. If required, additional services may be provided to the family. Resources are distributed among children in accordance with their needs and decisions taken by the municipal community [13].

In our country early intervention system is in the course of its formation [14]. Significant contribution to the formation of national experience of early intervention system is made by the Institute of Correctional Pedagogy of the Russian Academy of Education. The most important area of the scientific research conducted by the Institute is the search for optimal ways of reforming the special educational system and reorganizing it through completing the currently missing structural element, namely early detection and early comprehensive care.

The researches carried out in the 80 's of the $20^{\text {th }}$ century have already allowed to model and verify in practice the unified system of early detection and care for one category of infants and young children, specifically children with severe hearing impairments. Early support for children with hearing impairment during the first year of their life is provided in audiology rooms organized on the basis of special preschool educational institutions, children's hospital units and psycho-medical-social treatment centers. At the initial stage of early support multiple medical correction, early surgical and pharmaceutical treatment, hearing aids are provided. For the children from 1 to 2 years special sessions with audiology teachers are organized 2 or 3 times a week. For those children that live in remote areas from an audiology center, classes are organized daily over the course of 1 or 2 weeks two or three times a year. This model of early detection and comprehensive care for children with hearing impairments was the basis for the development of the unified state system of early care for children with other groups of developmental disorders, as well as for children of risk groups. The Institute of Correctional Pedagogy of the Russian Academy of Education is currently developing a program to create the unified state system of early identification and early intervention for children with developmental disabilities. Since the mid-90's the Ministry of Education of the Russian Federation put forward a priority task of creating the system of early intervention for children with developmental delays [15].

Approbation of different models of early intervention in Moscow was carried out through a system of medical - psychological pedagogical patronage in existing psychological - medical - social centers, psychological - medical - pedagogical consultation centers, in some institutions of preschool education, preschool educational institutions of the healthcare system, non-governmental organizations and services. Several testing sites were functioning in the framework of the Moscow Family - the Competent Parents, Capital Education city programs for the development and approbation of early intervention models for children with disabilities and activity limitations, as well as for children that belong to at risk groups [16].

The Saint Petersburg Institute of Early Intervention was established in 1992 due to the efforts of Professor L. A. Chistovich who was actively involved in the public life of the early 90's and began to promote the principles of early intervention. Importance of the first three years of a child's life for the formation of a child's brain and awareness of nonreversible consequences if the opportunity to help was missed were the fundamental principles for the creators of the program. Although one of the first ideas of L. A. Chistovich was to identify the impaired hearing of newborns and use the early prosthetic that in those years was still almost incredible. This activity spread rather quickly to all areas of support provided to young children. From the beginning western colleagues provided a great assistance in creating programs in Saint Petersburg.

In 1992 the Swedish Support Association of the Institute was established and headed by Arne Rizberg, his colleagues from the Royal Institute of Technology, the Stockholm Pedagogical Institute and informal support group from the United States that included Professor Mack Piketty and his colleagues from the Massachusetts Institute of Technology.

The idea of creating early intervention programs in Saint Petersburg generated an interest and was supported by many famous Russian medical scientists, namely Chief pediatrician of Saint Petersburg, Professor, I. Vorontsov, Otorhinolaryngologist, Professor, M. Kozlov, Ophthalmologist, Professor, V. Volkov, Neonatologist, Professor, Tsybulkin, Child neurologist, Professor, Garmashov, Chief pediatric neurologist of Saint Petersburg, Associate Professor, Candidate of Medical Science, T. Lazebnik, Professor, M. Nikitina, Chair of the Department of Children's Speech, Professor, S. Zeitlin, Professor, N. Traugott, Doctor of Psychological Science, A. Cornev participated in 
the development and adaptation of methods, assessment scales for early intervention. L. Chistovich and Y. Shapiro initiated adaptation and standardization of KID and CDI assessment scales that for a long time were the only normalized scales of a child's development.

It was the first and a very important step in the development of early intervention programs in Russia and establishment of the Saint Petersburg Institute of Early Intervention. Physiologists of speech, hearing, vision systems, linguists and cognitive psychologists previously involved only in fundamental researches, since then were engaged in practical work with young children.

In 1991 a temporary creative team under the guidance of $\mathrm{L}$. Chistovich wrote the Babies Habilitation Program aimed at detecting, correcting and substituting hearing, vision, movement, speech impairments and mental retardation of young children. At the same time the administration of Dzerzhinsky district supported the initiation of early intervention practical activity in the kindergarten №41. In 1992 the Babies Habilitation became a priority of the urban social program and was funded by the decision of the Small Council of Saint Petersburg Municipal Council of People's Deputies. L. Chistovich and E. Kozhevnikov became the co-managers of the program. The non-governmental institution called the Saint Petersburg Institute of Early Intervention was established especially for the development and implementation of the above-mentioned program. In July 1992 the Russian-Swedish Lekotek was created within the structure of the kindergarten № 41 of Dzerzhinsky district. The research officer of the Department of History and Philosophy of Science, Candidate of Biological Science R. J. Mukhamedrakhimov became the Director of the Lekotek. In the course of the time the program of lekotek activity developed into the multidisciplinary family-centered early intervention program.

From 1992 to 2003 the Saint Petersburg City Administration supported the development of early intervention programs. Initially the exercise and mastering of early intervention methods were funded in the framework of the Babies Habilitation Program, later funds were allocated within the Children with Disabilities Program for the development of habilitation services in children's clinics, testing of the services model, types of evaluation and multidisciplinary activity. Through the involvement of the Institute a new specialty of physical therapy was being developed in Russia, the specialty that is currently being successfully developed at the Saint Petersburg State Medical University named after academician I. P. Pavlov.

During the period from 2002 to 2005 the Institute was a clinical site for the development of ergotherapy. The necessity of changing the environment and surrounding in order to normalize the life of people with disabilities gradually became one of the fundamental values and principles of early intervention.

On the basis of the regional experiments in the educational sphere of the late 90's - early 2000's a network of early intervention services was established in Samara, Novgorod regions and Saint Petersburg. Kaliningrad, Rostov, Pskov, Moscow and Leningrad regions, Krasnoyarsk and Khabarovsk territories, Moscow and some other regions were involved in organizing early intervention services.

In January 2001, early intervention services for children from birth to age 3 started operating in Tomsk. The service was established by the Tomsk regional public foundation "Center of Identity Development" with financial support from the Open Society Institute of Soros Foundation. An interdisciplinary team of professionals with extensive experience in working with developmentally delayed children was organized within the service (Razenkova, 2013). In 2000 early intervention service was created in the Novgorod Children's Center in Veliky Novgorod (also Novgorod the Great). In 2003 early intervention services unit was opened on the basis of the municipal educational institution "Center for Psychological, Medical and Social Support". Early intervention services were successively opened in the cities of Novgorod region, in particular Borovichi (March 2001), Staraya Russa (March 2001), Valday (February 2002), Parfino urban-type settlements (September 2001) and Demyansk (March 2002).

On March 1, 2000 early intervention unit of the SupportiveExperimental Rehabilitation Center for children with disabilities was opened in Arkhangelsk. In 2003 the Development of Habilitation Practical Forms project was carried out with the support of the Open Society Institute and the Soros Foundation.

Formation of early intervention services for children with developmental disabilities in the Russian regions proceeds in two ways: generally, their formation is related to the priorities of the federal subject authorities and the current social policy that depends on the level of socio-economic development of the region. Such services can be classified as "created from above", their formation and development is based on the program-target method of managing the education. In the second case, the starting point for the creation of early intervention services is recognition of the motivation and necessity of the earliest possible detection of existing developmental disorders or risk factors of their emergence by professionals working directly with children of preschool age [17].

In 2008 experts of the resource centers in Saint Petersburg, Novgorod, Kharkov, Minsk created the Association of Early Intervention. They expressed concern that views and interests of multidisciplinary teams working in the early intervention services, as well as views and interests of families with children in need that know the situation from within, are not taken into consideration while adopting the legislation. Therefore, it was decided to create the Association of Early Intervention advocating for the development of early childhood services in the Eastern European countries on the basis of the entire use of all main principles such as scientificity, conclusiveness, systematic evaluation by using valid methods, interdisciplinary, active family involvement and other important principles. The aim of the Association is to create in those countries conditions for effective research and practical activities in the field of early childhood and thereby promote further formation of professional community based on the scientific knowledge and advanced technology in providing early intervention for families and people with functional disorders.

Thus, European countries and the USA occupy the leading position in the world for the quality of early care provided for children with disabilities and children with different kinds of impairments. The history of its formation and development in these countries began in the 60 's of the $20^{\text {th }}$ century. European countries and the USA accumulated vast experience in providing early support for this category of children. Early childhood support system in the Russian Federation is in the course of its formation. Only in the 90 's of the $20^{\text {th }}$ century fulfillment of the missing element, specifically the system of early detection and early correction of multiple disorders in a child's development as the basis for the subsequent process of education, training and necessary condition for the social and educational integration became one of the priorities of the special education development. However, absence of the public policy in the field of early intervention for children with developmental disabilities and lack of its legal framework hinders active direction of the Russian regions towards formation of the above-mentioned system. 
Citation: Akhmetzyanova Al (2016) Formation and Evolution of Early Intervention for Children with Developmental Delays in Russia and Abroad. J Psychol Abnorm S1: 006. doi:10.4172/jpab.S1-006

\section{References}

1. Carpenter B, Blackburn C, Egerton J (2005) Early Childhood Intervention Analysis of Situations in Europe. Key Aspects and Recommendations. European Agency for Development in Special Needs Education.

2. Alisauskiene S (2009). Key aspects and recommendations in early childhood intervention. Conference paper, European Conference of Quality in Early Childhood Intervention. Budapest.

3. Pretis M (2009) Early Childhood Intervention in Austria. Early Childhood Intervention Across Europe Towards Standards, Shared Resources and National Challenges.

4. Guralnick MJ (2001) A Developmental Systems' Model for Early Intervention. In Infant and Young Children, Aspen Publishers, ISEI 14: 2

5. Akhmetzyanova Al (2014) The Development of Self-Care Skills of Children with Severe Mental Retardation in the Context of Lekoteka. World Applied Sciences Journal 29: 724-727.

6. Martsinovskaya TD (2001) History of psychology. Moscow: Academy.

7. Mukhamedrakhimov RG (2001) Mother and baby: psychological interaction. St. Petersburg, Saint Petersburg University publishing house.

8. Aksenova LI (2002) Early comprehensive care for children with developmenta disabilities as one of the priorities of the modern special (correctional) pedagogy. Defectology 3: 11-12.
9. Malofeev NN (2009) Special education in a changing world. Moscow: Education, Europe.

10. Sukhanova NN (2015) Neonatologist work experience in an interdisciplinary team of Russian-Swedish Lekoteka.

11. Razenkova UA (2012) The initial stage of formation of the system of early intervention in the US: historical excursus. Defectology, 4: 173-178.

12. Emelina OI (2013) Abroad formation of system of care of young children. Special education 3: 13-18.

13. Razenkova UA (2013) System of early intervention in Sweden. Defectology, 6: 71-79.

14. Ustinova El, Matutina ZS (2004) Early care for children with perinatal affection of the nervous system who was brought up in a children's home. Herald of the Tomsk State University, 283: 211-216.

15. Razenkova UA (2003). Regional policy in the field of early intervention: Problems and Prospects. Defectology, 4, 72 -78.

16. Nazarova NM, Aksenova LI, Andreeva LV (2008) Pedagogical systems of special education. Moscow: Academy.

17. Malofeev NN, Razenkova NA (2007) About development of early intervention services for children with developmental disabilities and children with disabilities in the Russian Federation. Defectology, 6: 60-68.
This article was originally published in a special issue, Children Psychology handled by Editor(s). Dr. Gérard Mercier, University of Besancon, France 